\title{
Retraction Note to: Primary Draining Vein Stenting for Obstructive Total Anomalous Pulmonary Venous Connection in Neonates with Right Atrial Isomerism and Functional Single Ventricle Improves Outcome
}

\author{
Masataka Kitano $^{1}$ - Takaya Hoashi ${ }^{2}$ Takashi Kakuta $^{2} \cdot$ Kazuto Fujimoto $^{1}$ - Akira Miyake ${ }^{1}$ Ken-ichi Kurosaki $^{1}$. \\ Hazime Ichikawa ${ }^{2} \cdot$ Isao Shiraishi $^{1}$
}

Published online: 19 June 2019

(c) Springer Science+Business Media, LLC, part of Springer Nature 2019

\section{Retraction Note to: \\ Pediatric Cardiology (2018) 39:1355-1365 \\ https://doi.org/10.1007/s00246-018-1902-z}

The authors have retracted this article [Kitano, M., Hoashi, T., Kakuta, T. et al. Pediatr Cardiol (2018) 39: 1355. https ://doi.org/10.1007/s00246-018-1902-z] because, contrary to the statement in the article, this research did not obtain ethics approval from the National Cerebral and Cardiovascular Center Institutional Review Board prior to submission of the manuscript to Pediatric Cardiology. All authors agree to this retraction.

Publisher's Note Springer Nature remains neutral with regard to jurisdictional claims in published maps and institutional affiliations.

The original article can be found online at https://doi.org/10.1007/ s00246-018-1902-z.

Masataka Kitano

kitanom@ncvc.go.jp

1 Department of Pediatric Cardiology, National Cerebral and Cardiovascular Center, Suita, Osaka, Japan

2 Department of Pediatric Cardiovascular Surgery, National Cerebral and Cardiovascular Center, Suita, Osaka, Japan 